\title{
The use of branching scenarios to improve pharmacology content application
}

\author{
Miranda Bouwer ${ }^{1}$, Jonathan Guerrero ${ }^{2}$ \\ ${ }^{1}$ Indiana University School of Medicine, ${ }^{2}$ Indiana University School of Medicine Department of \\ Clinical Pharmacology and Toxicology
}

\section{Background/Objective:}

The Indiana University School of Medicine currently has many resources to offer its medical students to aid in their studies. But, there are no interactive pharmacology modules available. Pharmacology lectures only make up a small portion of lectures, but contain significant material students are expected to know. Previously published studies demonstrate a positive impact of interactive modules on medical student education. The goal of this project is to create interactive pharmacology modules to identify if this improves knowledge of pharmacology and standards of care.

\section{Methods:}

To start, one topic in pharmacology was chosen from each of the three spring semester first year classes. UpToDate and primary literature articles were used to develop the content in each module to follow the most current guidelines. A Pressbook was created for each topic and $\mathrm{H} 5 \mathrm{P}$ was used to create the interactive branching scenarios which will be embedded in the learning management platform Canvas. Students are given information in the module and are expected to answer relevant questions. Based on the answer chosen, they either progress or have to answer the question again after receiving feedback. Each module contains approximately three to four questions that the students advance through. The modules will be implemented as part of the pre-work for the relevant lecture or small group and are intended to take up no more than 5-10 minutes of time.

\section{Results/Conclusion:}

Two survey questions will be added to the end of the course surveys for the three spring semester first year classes for the school year 2020-2021. These questions will assess student satisfaction and the module's usefulness.

\section{Potential Impact:}

Providing interactive, branching scenario activities may increase student satisfaction of pharmacology content, improve content application, and become a useful tool for future content in other courses as well. 